\title{
Variabilidade espacial da temperatura do ar com uso de transectos móveis em Erechim/RS, sob domínio polar em processo de tropicalização
}

\author{
Spatial variability of air temperature with mobile transects in Erechim/RS, in polar domain \\ tropicalization process
}

\author{
Jonathan Júlio Kegler1, Cássio Arthur Wollmann², Vagner Apollo Duarte, \\ Ismael Luiz Hoppe e Amanda Comassetto Iensse ${ }^{5}$ \\ ${ }^{1}$ Licenciado/Mestrando em Geografia, PPGGEO, UFSM, Santa Maria, Brasil \\ jonathankegler@hotmail.com \\ ${ }^{2}$ Doutor/Orientador, Departamento de Geociências, UFSM, Santa Maria, Brasil \\ cassio_geo@yahoo.com.br \\ 3,4,5Alunos de graduação, Curso de Geografia, UFSM, Santa Maria, Brasil \\ vagneraduarte@hotmail.com; ismael.hoppe@hotmail.com; comassettoamanda@gmail.com
}

\begin{abstract}
Resumo
O objetivo geral desta pesquisa consistiu em analisar a distribuição espacial da temperatura do ar na área urbana de Erechim/RS, sob domínio polar em processo de tropicalização. Para a realização desta pesquisa climática in loco necessitou-se a realização de trabalho de campo com execução da metodologia de transectos móveis. Mediu-se a temperatura do ar às $15 \mathrm{~h}$. Foi confeccionado mapa de variação espacial da temperatura do ar registrada no ambiente urbano e utilizou-se de cartas sinóticas, imagens de satélite e dados da rede oficial de estações meteorológicas do INMET para identificação dos sistemas atmosféricos atuantes e comparações com os dados e sua magnitude. Após análise climática e cartográfica, observou-se que as variações térmicas nesta pesquisa primária, ocorreram de forma significativa, registrando-se diferenças de até $8^{\circ} \mathrm{C}$ entre os bairros da cidade, e a amortização que áreas verdes podem exercer neste ambiente, com redução em até 50\% das temperaturas mais elevadas registradas em Erechim. Ainda, para esta cidade, a orientação de vertentes e presença de corpos hídricos, foram fundamentais para a diferenciação espacial da temperatura em comparação com as áreas industriais, periféricas de baixa renda e centrais/comerciais.
\end{abstract}

Palavras-chave: Variabilidade espacial. Temperatura do ar. Área urbana. Erechim/RS. Circulação Atmosférica Regional. Domínio Polar. Tropicalização.

\begin{abstract}
This research concerns in to analyze the spatial distribution of air temperature in the urban area of Erechim/RS, under polar domain tropicalization process. In carrying out this climate research in loco needed to conduct field work with implementing the mobile transects methodology. Was measured air temperature 15 PM. It was made spatial variation map of air temperature recorded in the urban environment and used the synoptic maps, satellite imagery and data of the official network of weather INMET stations for identification of active weather systems and comparisons with the data and its magnitude. After climate and cartographic analysis, it was observed that the thermal variations on this primary research, occurred significantly, registering differences of up to $46,4^{\circ} \mathrm{F}$ between the districts of the city, and amortization that green areas can play in this environment, reducing up to $50 \%$ of the highest temperatures recorded in Erechim. Still, for this city, slope aspect and the presence of water bodies, were very important to the spatial differentiation of temperature compared to the industrial areas, low-income peripheral and central/commercial.
\end{abstract}

Keywords: Spatial variability. Air temperature. Urban area. Erechim/RS. Regional Atmospheric circulation. Polar domain. Tropicalization. 


\section{Introdução}

A sociedade está buscando cada vez mais as cidades para viverem, além do incremento à população já existente agregando funções do campo a cidade, para que haja cada vez menos a dependência do meio rural. Diversas mudanças acabam por ser ocasionadas com estas alterações na paisagem, e problemas provenientes desta ocupação muitas vezes acelerada e sem planejamento passam a existir. Com o tempo, as cidades começaram a expandir-se e aglomerar-se paulatinamente, adquirindo novas funções.

Santos (1993) coloca que no Brasil a agricultura comercial e a expansão mineral foram a base de um povoamento e uma criação de riquezas redundando na ampliação da vida de relações e no surgimento de cidades no litoral e no interior do país. A mecanização do campo ocasionou uma demanda populacional para as cidades na busca de novas oportunidades de emprego, já que a mão de obra no campo foi substituída pelas máquinas.

Nesse sentido as cidades começaram a receber novas funções, as quais atraíam cada vez mais a população excedente do meio rural, proporcionando um aumento no número de pessoas, e por consequência deste aumento, problemas começaram a surgir relacionados com a ocupação e modificação do meio natural de forma pouco ordenada. Ainda com o aumento da demanda para as cidades, a população se deparou com a falta de empregos necessários, nem a existência de bens e serviços essenciais, um empobrecimento da população e uma degradação de suas condições de existências.

No Brasil, o processo de urbanização corporativa também é um grande problema no desenvolvimento das cidades brasileiras. Santos (1993) afirma que a urbanização corporativa é empreendida sob o comando dos interesses das grandes firmas, constitui um receptáculo das consequências de uma expansão capitalista devorante dos recursos públicos, uma vez que estes são orientados para os investimentos econômicos, em detrimento dos gastos sociais.

Nesse sentido, os problemas climáticos são mais perceptíveis pelas pessoas que habitam a cidade, e que são sentidos no dia a dia da sociedade. Para MENDONÇA (1994) o clima urbano é o resultado das interações no ambiente natural, tais como a retirada da cobertura vegetal, modificação nas formas de relevo e na rugosidade da superfície, concentração de edificações, equipamentos e pessoas, impermeabilização do solo, canalização do escoamento superficial, acumulação de partículas e gases na atmosfera e produção de energia artificial.

A diferença do clima entre as cidades e o campo já eram mostradas nos primeiros registros meteorológicos, e então, comentadas no pioneiro estudo do clima de uma cidade, feito por Howard (1833) em Londres. Este estudo passou a ser referência, e é tratado em diversas monografias que tratam do tema, e expandiu-se a litera-

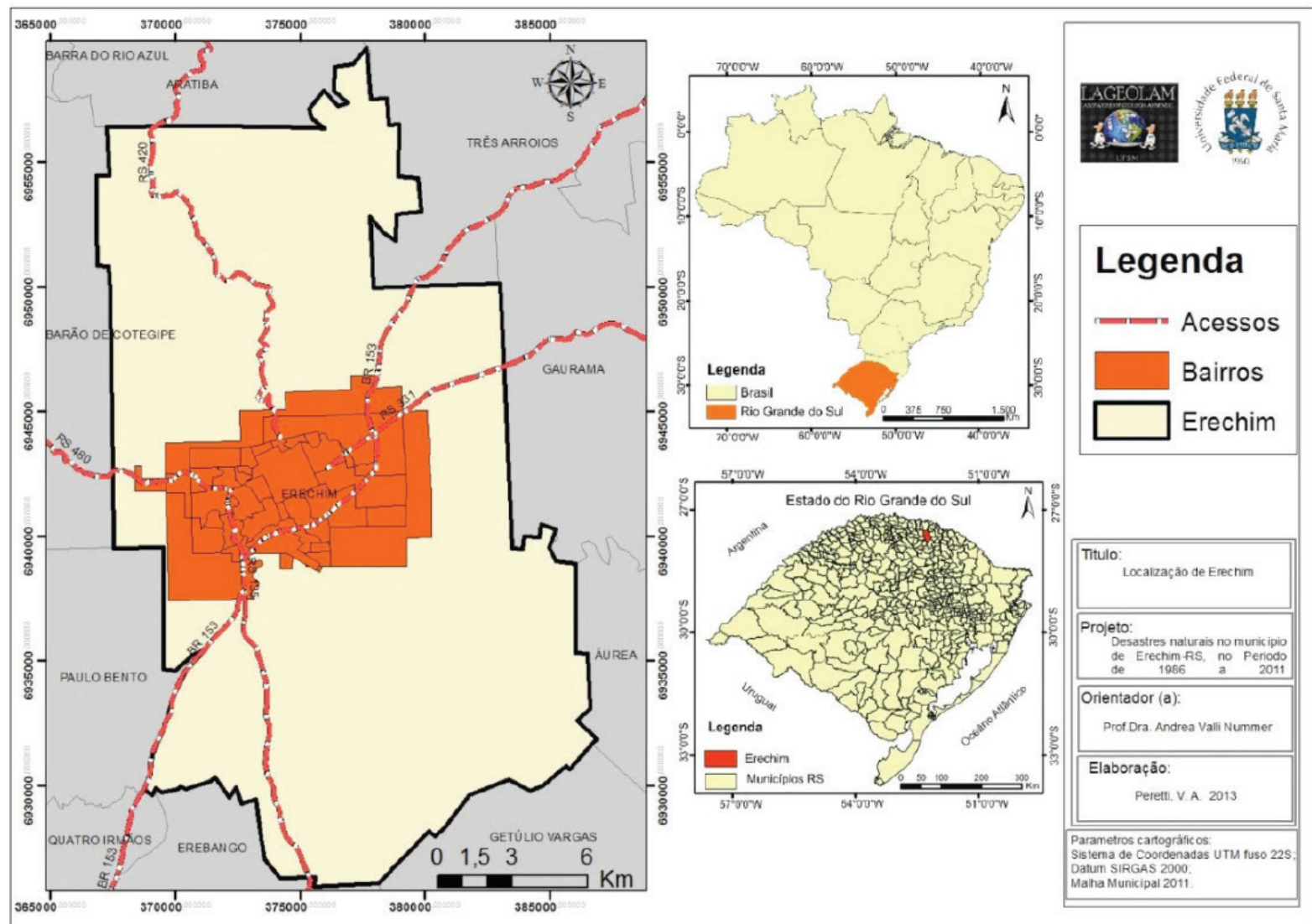

Figura 01 - Mapa de localização do município a área urbana de Erechim/RS

Fonte: Peretti, et. al. (2015, p. 257). 
tura incluindo estudos sobre a influência dos povoados e da indústria no clima.

Nesse contexto, o objetivo desta pesquisa foi o de analisar a distribuição espacial da temperatura do ar na área urbana de Erechim/RS, às 15 horas, em condições de domínio polar tropicalizado.

\section{Caracterização da Área de Estudo}

O município de Erechim/RS, localizado entre as coordenadas $27^{\circ} 38^{\prime} \mathrm{S}$ e $52^{\circ} 16^{\prime} \mathrm{W}$ (Figura 01), com uma população segundo estimativa do Instituto Brasileiro de Geografia e Estatística (IBGE, 2014), em 101.752 habitantes, e destes, mais de $90 \%$ habitam no meio urbano. Nesta região, desenvolvem-se atividades agrícolas (cultivo de soja e milho) e agropecuária extensiva. Sua área municipal é de $430,76 \mathrm{~km}^{2}$.

Segundo a SEPLAG (2006), o município de Erechim situa-se no Planalto da Serra Geral e faz parte da Bacia do Paraná, que e composta por uma sequência de derrames de rochas vulcânicas pertencentes a Formação Serra Geral. Na região Noroeste possui uma grande concentração de jazidas de ametista do estado. Stre-

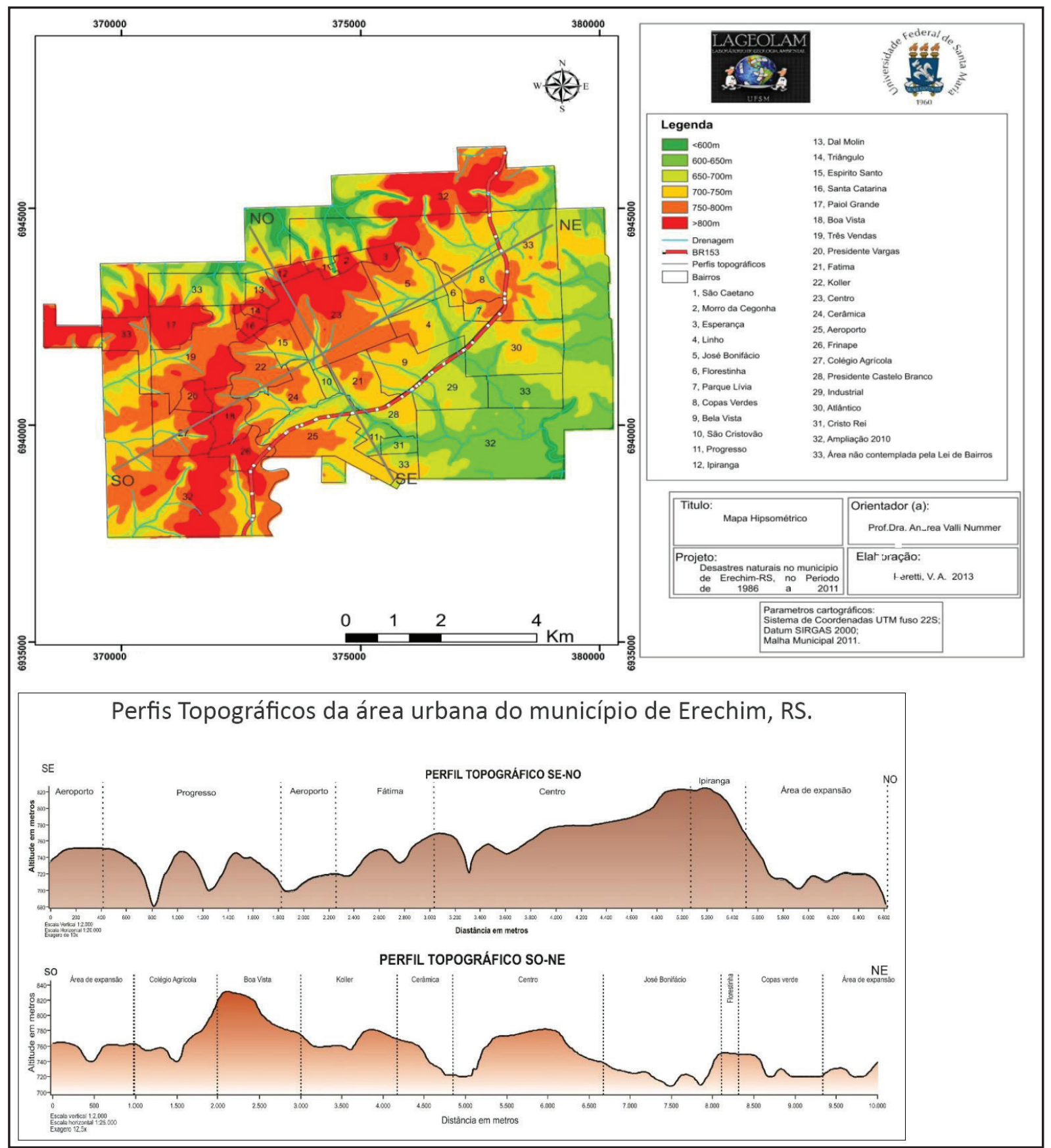

Figura 02 - Hipsometria e perfis topográficos da área urbana de Erechim - RS

Fonte: Peretti, et. al. (2015, p. 260) 
ck et. al. (2008) classificam os solos de Erechim como Latossolo Vermelho aluminoférrico típico (Unidade Erechim), apresentando as seguintes características boa drenagem, normalmente profundos com uma sequência de horizontes no seu perfil.

A área urbana está localizada em cotas altimétricas da ordem de 800 metros acima do nível do mar (Figura 02). Está situada nas proximidades do interflúvio de duas bacias hidrográficas pertencentes à região Hidrográfica do Rio Uruguai, Bacia do Passo Fundo, Várzea e a Bacia do Apuaê-Inhandava. (SEMA, 2009).

O estado do Rio Grande do Sul apresenta clima subtropical, onde Erechim faz parte da Zona Subtropical, possuindo um clima Mesotérmico brando superúmido sem seca, apresentando chuvas bem distribuídas ao longo do ano. (SARTORI, 1993).

O município se destaca no setor industrial, comercial e de serviços, sendo impulsionado pelo Parque Industrial voltado ao setor metal-mecânico e agroindustrial, estando em vigésima primeira posição em participação no Produto Interno Bruto do Estado, de acordo com dados da Fundação de Economia e Estatística - FEE/ RS. (FUNFGELT, 2004).

\section{Materiais e Procedimentos Metodológicos}

\subsection{Dos instrumentos utilizados e preparação para os trabalhos de campo (transectos mó- veis)}

Para realizar este trabalho referente ao estudo do campo térmico de Erechim/RS, utilizou-se de alguns procedimentos metodológicos a seguir discriminados.

A proposição metodológica adotada nesta pesquisa segue a já consagrada Teoria do Sistema Clima Urbano (SCU) de MONTEIRO (1976), que é um referencial teórico-metodológico da Geografia, amplamente utilizado nas pesquisas do clima urbano das cidades brasileiras.

Para a aquisição dos dados de temperatura do ar na zona urbana de Erechim, foi empregada a metodologia dos transectos móveis, a qual consiste na aquisição automática e simultânea de dados climáticos ao longo do trajeto dentro da malha urbana.

Para tal foram estabelecidos dois transectos cortando a cidade de Erechim nos sentidos leste-oeste e norte-sul (Figura 03). A realização do transecto ocorreu no horário das 15 horas, com condições de tempo estável, céu limpo e pouco vento (calmaria).

O trabalho de campo foi realizado no dia 07 de junho de 2013, em condições meteorológicas favoráveis para a coleta dos dados.

Para a aquisição dos dados foram utilizados dois termo-higrômetros, com registradores digitais, modelo HT 500 Instrutherm. Tais registradores são pré-programáveis e automáticos. Os aparelhos foram programados para realizar a aquisição automática dos valores de temperatura e umidade relativa do ar a cada 10 segundos à medida que serão realizados os transectos, com utilização de automóvel, a uma velocidade média de deslocamento entre 20 e $30 \mathrm{~km} / \mathrm{h}$.

Para a aquisição dos dados ao longo dos transectos foram utilizados dois automóveis particulares, e cada um fez um trajeto (transecto), tendo o mesmo horário de

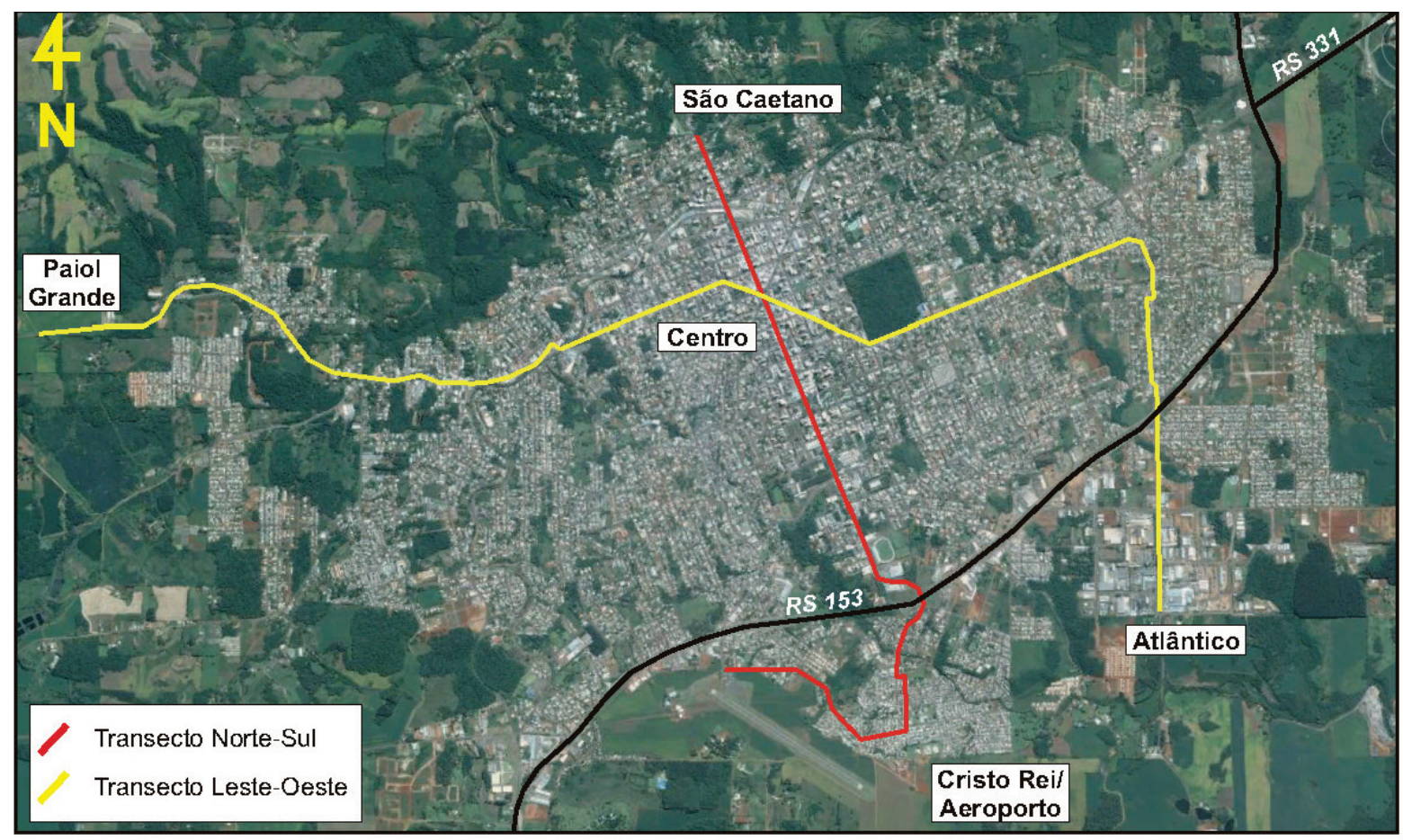

Figura 03 - Transectos móveis realizados na área urbana de Erechim - RS

Org.: Os autores 

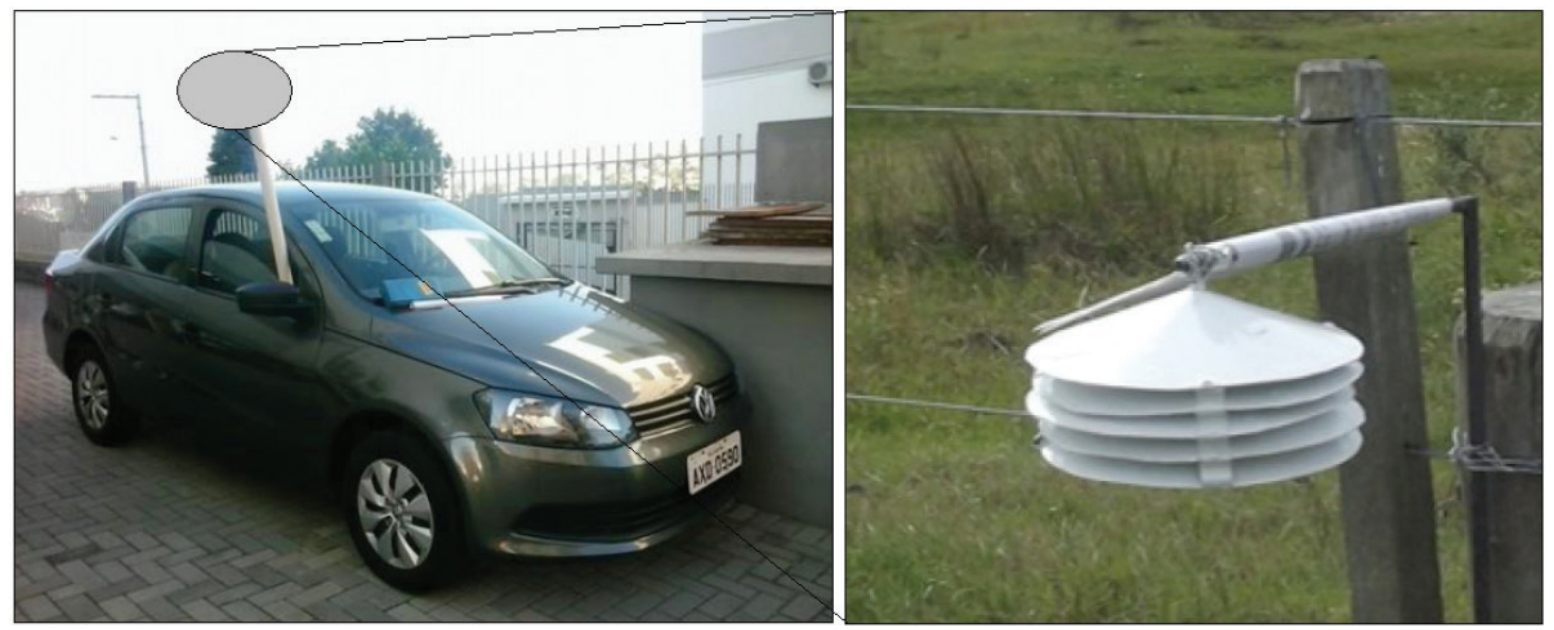

Figura 04 - Um dos automóveis utilizados para a aquisição dos dados de temperatura do ar na zona urbana de Erechim/RS, e estrutura em ferro galvanizado pintada de branco próximo à porta do veículo, onde foi colocado o instrumento

Fotos: $\mathrm{O}$ autor

início. Sendo necessários dois integrantes em cada carro: um condutor e um para o manuseio dos equipamentos.

A velocidade padrão dos automóveis ao percorrem os transectos nos horários de aquisição dos dados foi, em média, de 20 a $30 \mathrm{~km} / \mathrm{h}$ a fim de evitar a influência do vento nos registros feitos pelos aparelhos. O tempo percorrido pelos automóveis em cada transecto não ultrapassou 30 minutos, a fim de evitar uma maior discrepância dos dados entre o início e o final de cada trajeto.

Em cada automóvel, na lateral do veículo próximo a porta onde no interior da mesma foi inserido o aparelho (Figura 04), juntamente com uma estrutura em ferro galvanizado pintado com tinta branca, que é um miniabrigo meteorológico, para que o datalloger não fique em contato direto com o vento provocado pelo deslocamento do carro, com a finalidade de não serem produzidas distorções nos registros em campo.

Tanto os termômetros quanto os miniabrigos meteorológicos são materiais de pesquisa pertencentes ao Laboratório de Climatologia Geográfica, do Departamento de Geociências da Universidade Federal de Santa Maria, e sua eficiência já foi testada em trabalhos anteriores, conforme salientaram WOLLMANN; SIMIONI (2013) e HOPPE; et. al. (2015).

Houve a utilização também de dois localizadores GPS de navegação, um em cada carro, (marca Garmin modelo 400), para a aquisição de coordenadas planas do Sistema UTM (Universal Transversa de Mercator) ao longo dos transectos. Estes instrumentos pertencem ao Departamento de Geociências.

\subsection{Do mapeamento da temperatura em Ere- chim/RS}

Após a aquisição dos dados climáticos (temperatura e umidade relativa) e das coordenadas UTM, em campo, e no horário pré-estabelecido das 15 horas, os mesmos foram selecionados e tabulados em planilhas do Microsoft Excel 2010 a fim de serem utilizados no aplicativo Surfer 8.0 para a elaboração de cartogramas do campo térmico da zona urbana de Erechim/RS. O método de interpolação utilizado na elaboração dos cartogramas foi a krigagem ordinária do Surfer, conforme orientam WOLLMANN (2011) e WOLLMANN; GALVANI (2014).

Na elaboração do cartograma do campo térmico da zona urbana de Erechim, ao longo dos transectos, houve o uso de escalas de cores que variaram do verde claro para representar temperaturas mais baixas até o vermelho escuro para temperaturas mais elevadas. O mapa que espacializa os dados térmicos dos transectos realizados em Erechim, e ao final, procurou-se estabelecer a relação destas com a presença de elementos geourbanos e geoecológicos da área de estudo.

\subsection{Da análise sinótica nos dias de levanta- mento do sistema termodinâmico}

Houve a coleta de dados diários dos elementos climáticos, especialmente de temperatura do ar, umidade relativa do ar, pressão atmosférica e direção do vento da Estação Meteorológica de Erechim, para serem analisados e comparados com os dados coletados em Erechim no episódio de levantamento dos transectos móveis (junho de 2013).

Com o intuito de se determinar o tipo de tempo, os sistemas atmosféricos dominantes e a circulação atmosférica regional no dia de aquisição dos dados foram utilizadas imagens de satélite GOES-13 e cartas sinóticas de superfície, ambas disponíveis nas páginas do CPTEC/ INPE ( $\underline{w w w . c p t e c . i n p e . b r}$ ) e Marinha do Brasil ( $\underline{w w w . m a r}$. mil.br/dhn/chm/meteo/prev/cartas/cartas). 


\section{Resultados e Discussões}

\subsection{Variabilidade dos atributos do clima e identificação dos sistemas atmosféricos em Erechim/RS}

Após coleta dos dados em campo, foi feita coleta, no dia seguinte (08/06/2013) dos dados oficiais da Estação Meteorológica de Erechim, pertencente à Rede do Instituto Nacional de Meteorologia (INMET).

Tais dados foram catalogados e construiu-se a Tabela 01, com a qual se pode melhor visualizar a variação dos atributos do clima mensurados nesta estação.

De acordo com os dados da tabela 01, observa-se que ao longo do dia 07 de junho de 2013 foi observado em Erechim uma amplitude térmica de aproximadamente $15^{\circ} \mathrm{C}$ (diferença entre a máxima e mínima). Céu limpo durante o dia todo (nebulosidade zero) e obviamente sem ocorrência de chuva. Umidade Relativa do Ar alta nos períodos matutino e noturno, com significativo abaixamento no período da tarde. A direção do vento predominantemente de Norte, com velocidade máxima de $1,5 \mathrm{~m} / \mathrm{s}$, denotando alta estabilidade atmosférica. Pressão atmosférica levemente baixa, variando entre 1007 e 1010 mb. Nesse sentido, observa-se que o dia de realização do campo foi ideal para aplicação deste tipo de pesquisa climática e metodologia proposta.

Para a identificação dos sistemas atmosféricos, foram utilizadas as cartas sinóticas e imagens de satélite da 00h e 12h, conforme horários oficiais da Marinha do Brasil para confecção das cartas isobáricas, que podem ser melhor visualizadas na Figura 05.

De acordo com a Figura 05, observa-se que o Estado do Rio Grande do Sul, e consequentemente Erechim estão sob domínio do avanço de um Anticiclone Polar Atlântico e consequentemente sua Massa Polar Atlântica - MPA, cujo domínio deu-se com mais força a partir da carta e imagem das $12 \mathrm{~h}$, pois na imagem referente às 00h, o eixo da Frente Polar Atlântica (FPA) encontrava-se na divisa com o estado de Santa Catarina.

Esta situação sinótica apresenta o centro isobárico sobre as latitudes de $35^{\circ} \mathrm{S}$ sobre o continente (trajetória continental) registrando-se $1024 \mathrm{mb}$. Cruzando-se com os dados da Estação Meteorológica de Erechim, a direção predominante do vento neste dia era do quadrante Norte $(\mathrm{N})$, principalmente no período após as $12 \mathrm{~h}$, quando há a fusão de outro centro de alta pressão polar localizado sobre o estado de São Paulo, e consequentemente, com o Anticiclone Tropical Atlântico, elevando as temperaturas na parte da tarde.

De acordo com Sartori (1980; 1981) e Wollmann; Sartori (2009) pode-se classificar este quadro sinótico como de Domínio Polar na parte da manhã, mas já se aproximando às características de Domínio Transicional e configurando-se como tal na parte da tarde, que segundo WOLLMANN (2011, p. 122), podem ser colocados como:

Domínio Polar - Nesta fase as condições de tempo são impostas pelo domínio da Massa Polar Atlântica (MPA) no Rio Grande do Sul, resultando em grande declínio das temperaturas máximas e mínimas, podendo favorecer, dependendo da força desse sistema extratropical e da estação do ano, a ocorrência de geadas, orvalho, nevoeiro e até mesmo neve nas regiões mais elevadas do Planalto da Bacia do Paraná (Nordeste do Estado). Fase Transicional - É uma fase de "transição" entre o domínio da MPA e nova fase Pré-Frontal. Caracteriza-se pelo domínio da Massa Polar modificada pelo aquecimento basal sobre latitudes mais baixas (Massas Polar Velha (MPV) ou Tropicalizada) em função do tempo de permanência do ar frio no Sul do Brasil. Em função da superfície continental e da forte insolação facilitada pelo céu limpo, a MPA é modificada no interior do continente, aquecendo-se basalmente, resultando em uma massa de ar de origem polar mais quente e seca.

Nesse sentido, os dados coletados em campo e na Estação meteorológica de Erechim, com temperatura entre $4^{\circ} \mathrm{C}$ e $19^{\circ} \mathrm{C}$ (e amplitude de aproximadamente de $15^{\circ} \mathrm{C}$ ), umidade relativa do ar entre $68 \%$ e $100 \%$, e pressão atmosférica pouco abaixo dos valores de referência (1013mb) são as características comuns do Tempo Anticiclônico Polar em Tropicalização (SARTORI, 1981).

Tabela 01 - Dados dos atributos climáticos coletados na Estação meteorológica de Erechim/RS para o dia 07/06/2013

\begin{tabular}{|c|c|c|c|c|c|c|c|c|c|c|}
\hline \multirow[t]{2}{*}{ Data } & \multirow[t]{2}{*}{ Hora } & \multirow{2}{*}{$\begin{array}{l}\text { Temperatura } \\
\left({ }^{\circ} \mathrm{C}\right)\end{array}$} & \multirow{2}{*}{$\begin{array}{l}\text { Umidade } \\
(\%)\end{array}$} & \multirow{2}{*}{$\begin{array}{l}\text { Pressão } \\
(\mathrm{hPa})\end{array}$} & \multicolumn{2}{|c|}{ Vento } & \multirow{2}{*}{$\begin{array}{l}\text { Nebulosidade } \\
\text { (Décimos) }\end{array}$} & \multicolumn{3}{|c|}{ Dados diários } \\
\hline & & & & & $\begin{array}{l}\text { Vel. } \\
(\mathrm{m} / \mathrm{s})\end{array}$ & $\begin{array}{l}\text { Dir. } \\
\left({ }^{\circ}\right)\end{array}$ & & $\begin{array}{c}\text { Temp. } \\
\text { Máx. }\left({ }^{\circ} \mathrm{C}\right)\end{array}$ & $\begin{array}{c}\text { Temp. } \\
\text { Mín. }\left({ }^{\circ} \mathrm{C}\right)\end{array}$ & $\begin{array}{l}\text { Chuva } \\
(\mathrm{mm})\end{array}$ \\
\hline $7 / 6 / 2013$ & 09 & 7,4 & 97 & 1009,2 & 0,0 & 0,0 & 0 & & 4,6 & 0,0 \\
\hline $7 / 6 / 2013$ & 15 & 19,2 & 68 & 1007,4 & 1,5 & 5,0 & 0 & & & \\
\hline $7 / 6 / 2013$ & 21 & 11,2 & 100 & 1010,2 & 0,0 & 0,0 & 0 & 19,4 & & \\
\hline
\end{tabular}

Fonte: INMET - Estação meteorológica de Erechim/RS

Org.: Os autores 


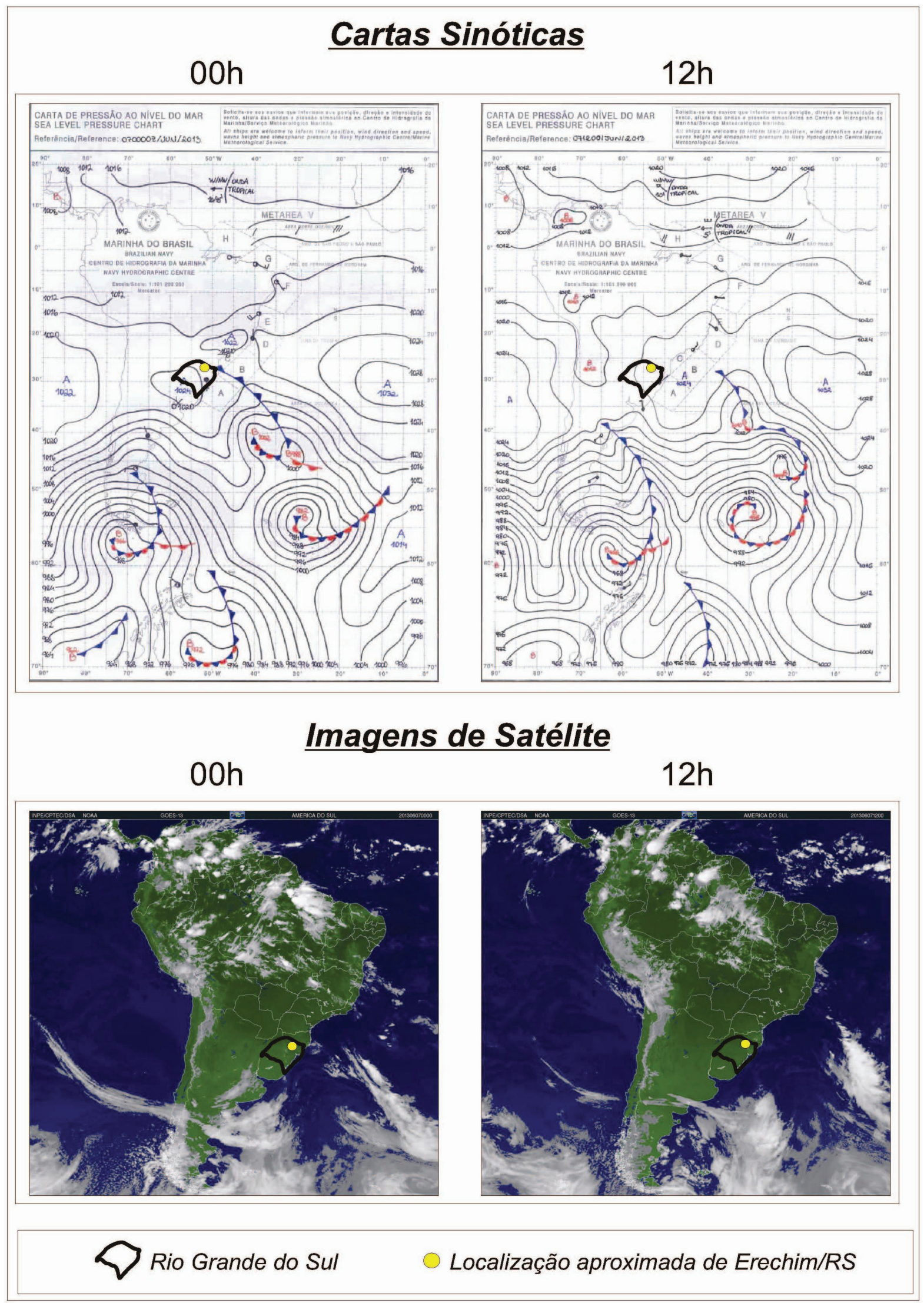

Figura 05 - Cartas Sinóticas e Imagens de Satélite do dia 07/06/2013, com destaque para a localização de Erechim/RS Fonte: Cartas Sinóticas da Marinha do Brasil / Imagens de Satélite CPTEC/INPE.

Org.: Os autores 


\subsection{Variação espacial da temperatura na área urbana de Erechim/RS}

Consoante à metodologia proposta para esta pesquisa, realizou-se o mapeamento da variabilidade espacial da temperatura do ar na área urbana de Erechim a fim de que se possa observar se houve relação entre a mesma e os diferentes ambientes urbanos. Nesse sentido, a Figura 06 apresenta a variabilidade espacial da temperatura média do ar registrada às $15 \mathrm{~h}$ conforme levantamento feito pelos transectos.

De acordo com a Figura 06, analisando-se a temperatura do ar às $15 \mathrm{~h}$ na área urbana, observou-se que a cidade de Erechim sofre uma influência muito grande dos seus componentes urbanos. A disposição das edificações e a distribuição das áreas verdes também acabam por influenciar nas temperaturas da cidade.

As maiores temperaturas foram constatadas no centro da cidade e nos bairros próximos onde está localizado o pólo industrial (Linho, Atlântico, Industrial, Florestinha e Parque Lívia), que por sinal, são bairros com menor renda per capita, de acordo com dados do censo do IBGE (2010). Apesar da presença de áreas verdes, as fábricas e indústrias acabam por influenciar no aumento das temperaturas, a emissão de gases poluentes e a presença de construções voltadas para a acomodação das indústrias acabam por ocasionar a constatação de temperaturas mais elevadas.

Em comparação com os dados registrados na Estação Meteorológica de Erechim, esta área da cidade foi a que apresentou maior magnitude, com temperaturas cerca de $8^{\circ} \mathrm{C}$ acima do registrado no dado oficial.

O centro da cidade é outro ponto que se encontram temperaturas mais elevadas com relação ao restante da cidade. Fatores como maior concentração populacional, maior deslocamento de veículos, por consequência a emissão de gases e a suspensão de partículas e maior concentração de edificações ocasionam temperaturas elevadas. A orientação das vertentes na região central do município também acabam por influenciar nas temperaturas, onde a incisão dos raios solares é maior nas vertentes com orientação oeste e norte.

Como a medição foi realizada no horário das $15 \mathrm{~h}$ o Sol estava voltado para estas vertentes, conforme pode ser observado sua distribuição em Peretti, et. al. (2015), havendo assim um maior aquecimento desta, aumentando ainda mais o calor em comparação (cerca de $8^{\circ} \mathrm{C}$ ) com os dados registrados na Estação Meteorológica de Erechim, conforme os dados coletados e apresentados na tabela 01 .

Já nos bairros Cerâmica, São Cristovão, Progresso, Presidente Castelo Branco e Cristo Rei as temperaturas

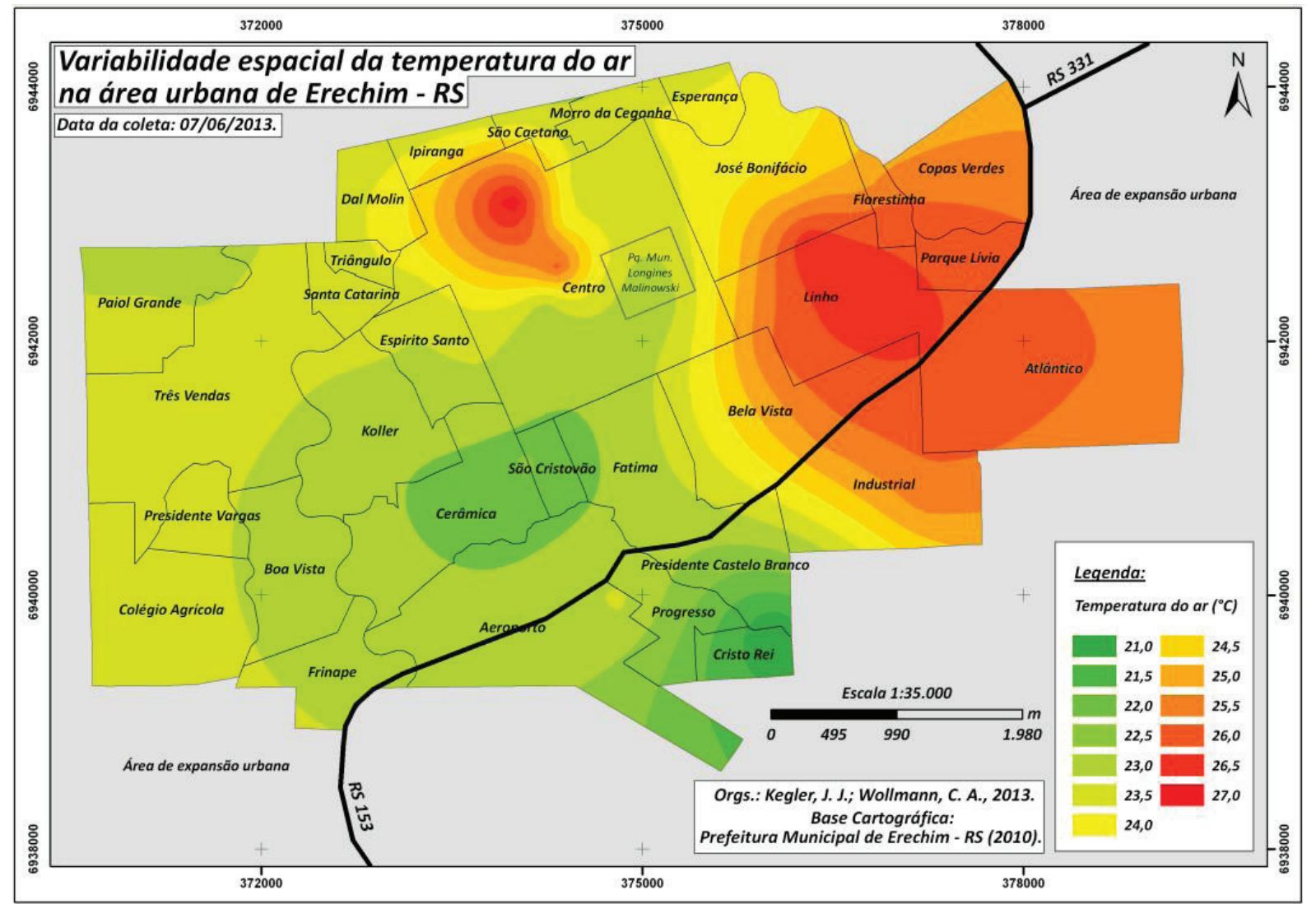

Figura 06 - Variabilidade espacial da temperatura média do ar na área urbana de Erechim/RS, às 15h, de 06 de junho de 2013.

Org.: Os autores. 
são mais amenas (mas mesmo assim cerca de 2 a $3^{\circ} \mathrm{C}$ maiores que o registrado na estação meteorológica) por apresentarem maior número de casas residenciais e áreas verdes, onde a altura das edificações e os espaços que há entre elas devido ao espaçamento da construção facilita a circulação dos ventos. Ainda, a presença de áreas verdes amenizam o calor, por apresentarem maior conservação da umidade e absorção do calor.

A circulação de pessoas e de veículos, por serem bairros majoritariamente residenciais, é muito menor se relacionados com outros locais da cidade, como o Centro, Ipiranga, Dal Molin e São Caetano, ocasionando as menores temperaturas constatadas na área urbana de Erechim. Outro ponto importante a ser observado é que nestes bairros da cidade, a orientação das vertentes é predominantemente de leste e sul, ocasionando menor incidência direta da radiação solar, contribuindo para um menor aquecimento nestes bairros. A presença de rios e arroios nestes bairros, como o Arroio do Tigre, principal curso d'água que atravessa a área urbana de Erechim (Figura 02) auxiliam na redução das temperaturas nos bairros localizados ao sul do Centro da cidade.

Ainda, no que tange as áreas da cidade com menor registro de temperatura, salienta-se os registros próximos ao Parque Municipal Longines Malinowski, principal parque urbano de Erechim, que apresentaram uma redução em cerca de $4^{\circ} \mathrm{C}$ a menos em comparação com o centro da cidade. Tal fato comprova o amortecimento que áreas verdes possuem sobre as temperaturas do ar registradas nos centros urbanos, para tal, sua implantação torna-se de suma importância para aumento da qualidade ambiental nas cidades.

\section{Considerações Finais}

Neste trabalho pretendeu-se estudar de forma inicial e preliminar o ambiente urbano de Erechim/RS e sua relação com um atributo do clima, tido pela literatura científica como a mais alterada por este ambiente: a temperatura do ar. A partir do referencial teórico abordado, dos dados coletados em campo (primários e secundários) e sua posterior análise, considerou-se alguns pressupostos observados e que impõem resultados à pesquisa.

Observou-se que a área urbana de Erechim, ainda que este município tenha sido planejado em sua fundação, mas com crescimento sem a mesma ordenação, causa uma influência muito grande na variação espacial da temperatura em comparação com os dados oficiais da estação meteorológica, sendo registrada magnitude de até $8^{\circ} \mathrm{C}$ nas áreas mais centrais e industriais da cidade. Evidenciou-se também a importância das áreas verdes neste espaço urbano de Erechim, as quais promoveram, em alguns locais, redução de até 50\% das temperaturas registradas nos locais mais quentes e em comparação com os dados oficiais do INMET.

Salienta-se que esta variação térmica é resposta ao domínio de sistemas atmosféricos polares em processo de tropicalização (Massa Polar Atlântica, em Fase Transicional, com registro do tipo de tempo Anticiclônico Polar em Tropicalização), e que tais variações térmicas podem ocorrer com maior, ou menor, intensidade/magnitude dependendo dos tipos de sistemas atmosféricos e tipos de tempos inerentes em função da sequencia habitual dos tipos de tempo no Rio Grande do Sul, e consequentemente em Erechim. Para evidenciar tais fatos, salienta-se e realização de novas pesquisas neste ambiente urbano.

Com isso, acredita-se que este trabalho possa servir de base e motivar pesquisas futuras de clima urbano voltadas à cidade de Erechim/RS, dado ao seu ineditismo, e tais pesquisas serem incorporadas no planejamento climático urbano do município, uma vez que as cidades médias de todo o Brasil, bem como do Rio Grande do Sul, carecem de tais estudos.

\section{Referências}

AYOADE, J. O. Introdução à climatologia para os trópicos. Rio de Janeiro: Bertrand Brasil, 6. Ed. 2003.

FÜNFGELT, K. História da paisagem e da evolução urbana de Erechim - RS. Dissertação (Mestrado em Geografia). Universidade Federal de Santa Catarina. Florianópolis. 2004.

HOPPE, I. L. ; IENSSE, A. C. ; SIMIONI, J.P. D. ; WOLLMANN, C. A. Comparação entre um abrigo meteorológico de baixo custo e a estação meteorológica oficial no INMET, em Santa Maria (RS). Ciência \& Natura, v. 37, p. 132137, 2015.

HOWARD, L. The Climate of London Deduced from Meteorological Observations Made in the Metropolis and at Various Places around It. 2. Ed. 3 v. Londres: J. \& A. Arch, Cornhill; Longman \& Co. 1833.

INSTITUTO BRASILEIRO DE GEOGRAFIA E ESTATÍSTICA, Dados Demográficos 2010. IBGE, 2014. Disponível em <www.ibge.gov.br>. Acesso em 13 jul. 2014.

MENDONÇA, F. A. O Clima e o planejamento urbano de cidades de porte médio e pequeno: proposição metodológica para estudo e sua aplicação à cidade de Londrina - PR. 1994. 322f. Tese (Doutorado em Geografia)Universidade de São Paulo, São Paulo, 1994.

PERETTI, V. A.; NUMMER, A. V.; WOLLMANN, C. A. Análise espaço-temporal dos desastres naturais de origem meteorológica e climatológica no município de Erechim (RS), no período de 1986 a 2011. Boletim Gaúcho de Geografia. v. 42 - p. 255-275, 2015. 
SANTOS, M. A Urbanização Brasileira. São Paulo: EDUSP, 1993.

SARTORI, M. G. B. Distribuição das chuvas no Rio Grande do Sul e a variabilidade têmporo-espacial no período 1912-1984. In: SMPÓSIO BRASILEIRO DE GEOGRAFIA FÍSICA E APLICADA. 5. 1993, São Paulo. Anais... São Paulo: USP, 1993.

SARTORI, M. G. B. A circulação atmosférica regional e as famílias de tipos de tempo identificadas na região central do Rio Grande do Sul. Ciência e Natura, n. 3, p. 101-110, 1981.

SARTORI, M. G. B. Balanço sazonário da participação dos sistemas atmosféricos em 1973, na região de Santa Maria, RS. Ciência e Natura, n. 2, p. 41-53, 1980.

SARTORI, M. G. B. O clima de Santa Maria: do regional ao urbano. 1979. 163f. Dissertação (Mestrado em Geografia) - Universidade de São Paulo, São Paulo, 1979.

SECRETARIA ESTADUAL DE PLANEJAMENTO E DESENVOLVIMENTO REGIONAL - SEPLAN. Atlas Socioambiental do Rio Grande do Sul. Porto Alegre: SEPLAN/RS. 2006. Disponível em: <http://www. atlassocioeconomico.rs.gov.br>. Acesso em: 21 de março de 2015.

STRECK, E. V. et. al. Solos do Rio Grande do Sul. Porto Alegre: UFRGS, 2008. 222p.

WOLLMANN, C. A.; GALVANI, E. Zoneamento Agroclimático - Aportes teóricos, metodológicos e técnicas para o estudo das roseiras (Rosaceae spp.) no Rio Grande do Sul. 1. Ed. Porto Alegre: Buqui Livros digitais, 2014. V. 1. 149p.

WOLLMANN, C. A; SIMIONI, J. P. D. Variabilidade espacial dos atributos climáticos na Estação Ecológica do Taim (RS), sob domínio polar. Revista do Departamento de Geografia - USP, Volume 25, p. 56-76. 2013.

WOLLMANN, C. A. Zoneamento Agroclimático para a Produção de Roseiras (Rosaceae spp.) no Rio grande do Sul. 386p. 2v. Tese (Doutorado em Geografia Física). Programa de Pós-graduação em Geografia Física, Universidade de São Paulo, 2011.

WOLLMANN, C. A.; SARTORI, M. G. B. O Clima do Rio Grande do Sul No Verão: Análise Sobre a Circulação Atmosférica Regional e os Principais Tipos de Sucessão do Tempo em Três Casos Típicos. Revista Geografia Ensino \& Pesquisa, v. 13, p. 33-43, 2009a.

WOLLMANN, C. A.; SARTORI, M. G. B. Frequência mensal e sazonal da participação de sistemas atmosféricos no verão do Rio Grande do Sul: análise sobre três casos típicos (1986/1987, 1997/1998 e 2004/2005). Revista Ciência e Natura, v. 31, p. 141-161, 2009b. 